\title{
Tropical Rain Forest Monitoring and Evaluation using Image Segmentation Approach
}

\author{
Abdul Aziz K Abdul Hamid, R.U. Gobithaasan, Sumazly Sulaiman, NurSyazwani \\ Universiti Malaysia Terengganu \\ Kuala Terengganu, Terengganu, Malaysia
}

\begin{abstract}
The tropical deforestation is now being tracked by actors in the nongovernmental, academic, private and government sectors using several different sources of satellite imagery. This paper proposes a satellite image analysis system that can be used for deforestation related examination and monitoring activities in the tropics. In this paper, the extraction of deforestation area based on the image grey level information and the adaptive threshold were obtained by Otsu threshold method. Then, the edge of the image is smoothen and dilated to outline the deforestation area. Finally we calculate the area of deforestation by summation of all the white pixel. Experiments show that the proposed method has acceptable accuracy rate which above $96 \%$ when compared with ground truth data.
\end{abstract}

Keywords: Tropical Deforestation, Image Segmentation, GIS, Image Analysis

\section{Introduction}

Forest is a precious resource for human existence and development of sustainability. Due to the influence of human factors and economical greed, forests have been exposed to uncontrolled deforestation, which badly damages the forest ecosystem and threatens the security of natural habitat. Deforestation is considered to be one of the most destructive natural disasters affecting the development of society, environment and economy.

The demand for the tropical timber and high price of wood product contribute to the deforestation activities. The trends of logs export are divided into species and destination. Meranti (Shorea spp.) is the major species of logs exported, follow by Balau and Selangan Batu as shown in Table 1. The trend of logs exported by destinations are shown in Table 2 where Japan is the major importer of logs followed by China and India. China had reduced their volume of logs imported from Malaysia due to ply mills factories consuming softwood which is cheaper than tropical logs. India imports a huge amount of tropical logs since lack of local tropical logs supply for construction such as housing, building and for other purposes.

According to a new global forest map developed in partnership with Google, Malaysia had the world's highest rate of forest loss between 2000 and 2012. Malaysia's total forest loss during the period amounted to 14.4 percent of its year 2000 forest cover as shown in Fig 1. The loss translates to 47,278 square kilometers (18,244 square miles), an area larger than Denmark. Therefore, deforestation prevention and monitoring is an arduous long-term activity which is essential to maintain the equilibrium of Malaysia's natural ecology.

In the contact of Malaysia tropical rain forest zones, an aerial forest protection is the most convenient way for the forest rangers. Traditionally rangers have been carrying out manual identification and it is a pain taking process to identify the size of deforestation area once deforestation is detected. In general, the method of defining the deforestation area is realized by using hand-held GPS. Since the forest is dense and difficult to walk through, helicopters are often used to measure the deforestation areas. However, this method fails to measure the area in time and causes a lag in terms of carrying out immediate action to combat illegal logging and deforestation. With constant development of computer technology, it is possible for rangers and forestry department officers to achieve the interpretation and identification of the deforestation areas by using image analysis technologies.

At present there is no access to a deforestation area and measurement was made based on ground estimation which is very hard. In a recent years, technological advancement in satellite imaging provided very easy and cheap solution to acquired forest image data. 
Table 1: Species of Malaysian Forest.

\begin{tabular}{|c|c|c|}
\hline Type & Local Name & Scientific name \\
\hline Heavy hardwood & $\begin{array}{l}\text { Chengal } \\
\text { Balau } \\
\text { Merbau } \\
\text { Belian } \\
\text { Resak }\end{array}$ & $\begin{array}{l}\text { Neobalanocarpus heimii } \\
\text { Shorea spp. } \\
\text { Intsia spp. } \\
\text { Eusideroxylon zwageri } \\
\text { Vatica spp. }\end{array}$ \\
\hline Medium hardwood & $\begin{array}{l}\text { Kempas } \\
\text { Keruing } \\
\text { Kapur }\end{array}$ & $\begin{array}{l}\text { Koompassia malaccensis Dipterocarpus spp. } \\
\text { Dryobalanops spp. }\end{array}$ \\
\hline Light hardwood & $\begin{array}{l}\text { Meranti } \\
\text { Rubberwood } \\
\text { Nyatoh } \\
\text { Ramin Kembang Semangkuk } \\
\text { Sepetir } \\
\text { Tualang } \\
\text { Jelutong } \\
\text { Sesendok } \\
\text { Durian }\end{array}$ & $\begin{array}{l}\text { Shorea spp. } \\
\text { Hevea brasiliensis } \\
\text { Sapotaceae spp. } \\
\text { Gonystylus spp. } \\
\text { Scaphium spp. } \\
\text { Sindora spp } \\
\text { Koompassia excelsa } \\
\text { Dyera spp. } \\
\text { Endospermum spp. } \\
\text { Durio spp }\end{array}$ \\
\hline Softwood & $\begin{array}{l}\text { Damar minyak } \\
\text { Podo } \\
\text { Sempilor }\end{array}$ & $\begin{array}{l}\text { Agathis borneensis } \\
\text { Podocarpus spp } \\
\text { Dacrydium spp }\end{array}$ \\
\hline
\end{tabular}

Table 2: Markets for Malaysian Major Timber and Timber Products.

\begin{tabular}{|l|l|}
\hline Major Products & Main Markets \\
\hline Logs & Japan, China, India and Taiwan \\
\hline Sawn timber & Thailand, European Union, China, West Asia, Japan, Singapore and Philippines. \\
\hline Plywood & Japan, South Korea, USA, Taiwan, UK, Singapore and West Asia. \\
\hline Veneer & China, South Korea, Taiwan, Philippines and Japan. \\
\hline Moulding & $\begin{array}{l}\text { Japan, USA, Netherlands, Australia, China, Taiwan, UK, Canada, Belgium, Germany, Singapore } \\
\text { and South Korea. }\end{array}$ \\
\hline Fiberboard & China, Japan, South Korea, United Arab Emirates, Taiwan, Saudi Arabia, Kuwait and Vietnam. \\
\hline Building, Carpentry \& Joinery & USA, UK, Singapore, Australia, Denmark, Germany, South Korea, Netherlands and China. \\
\hline Furniture & USA, Japan, UK, West Asia, Australia, Singapore and Canada. \\
\hline
\end{tabular}

The use of image processing technique provide several advantages such as fast estimation, reducing monitoring time and high accuracy compared to the conventional methods. Normally aerial image are used to monitor forest fire. Merino Luis et al developed a system for forest fire monitoring. The system uses the images taken from a helicopter and incorporated 
with the GPS positioning and link with the Geographic Information System (GIS) to locate the fire ground place [1]. In [2] they presented a technique for image segmentation that based on color (the L*a*b* color space is used), texture (using entropy) and image features (gradients) and used for classification of natural land surfaces and man-made structures while [3] introduced a new algorithm for combining color and texture information for the segmentation of color images. The algorithm which uses maximum likelihood classification combined with a certainty based fusion criterion is currently being designed to assist an operator in updating an old map of an area using aerial images.

\section{Major forest countries: Highest percentage forest loss, 2000-2012}

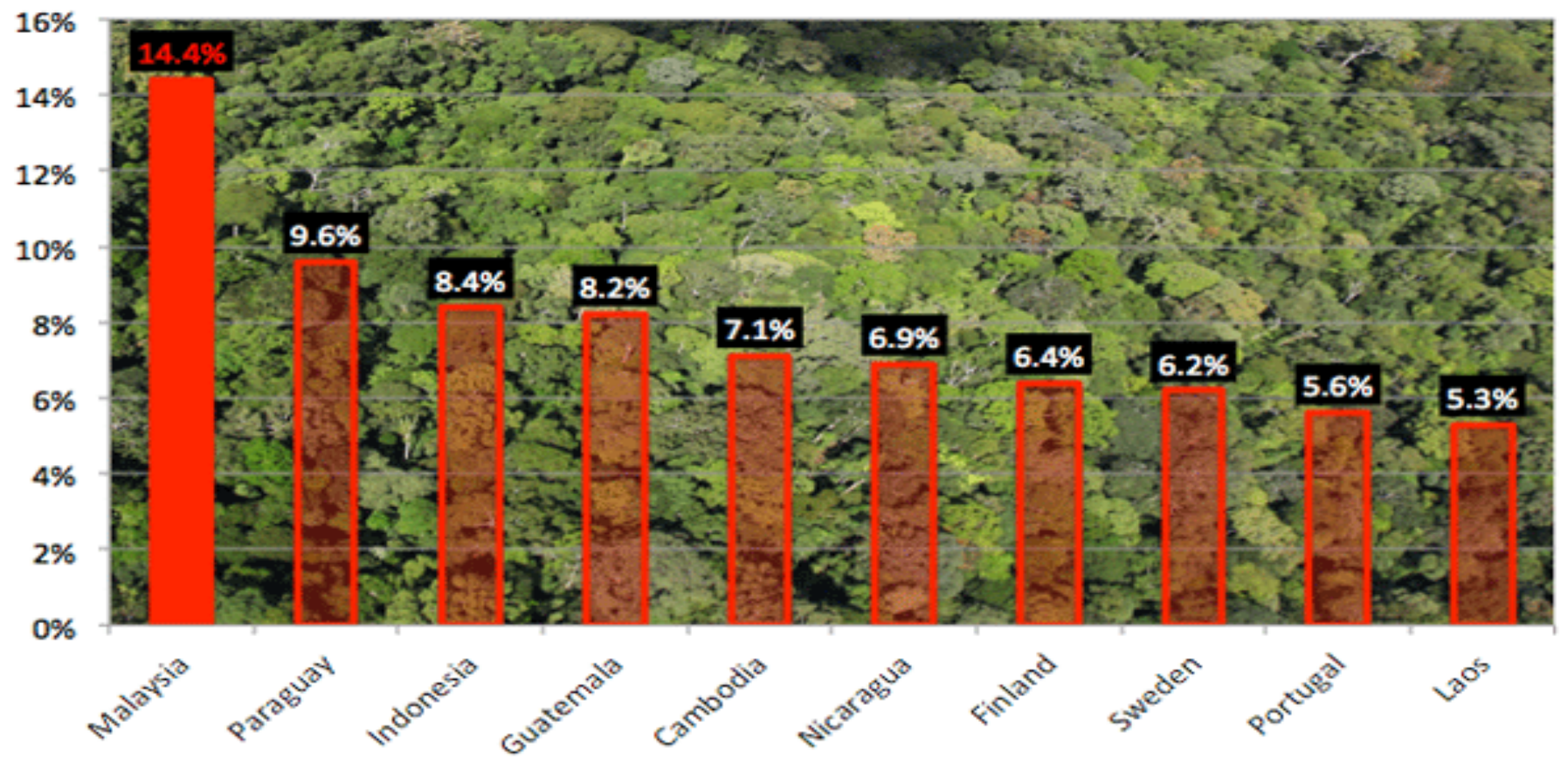

Fig. 1: Percentage of Forest Loss by Country (2000-2012) [4].

Based on the analysis of a large number of forest fire aerial images and the survey from the aviation forest rangers, the crown fire in aerial images during a forest fire disaster can been seen clearly where white fog were released from burning vegetation. Thus the fog area can be generally considered as the actual forest fire area. Zhang et al proposed a novel method to detect fire and smoke in two steps and obtain areas of fire and smoke together with the help of Otsu method [5]. Wang et al put forward a segmentation method of smoke in forest-fire image based on FBM and Region Growing [6]. Li et al presented an automatic statistical segmentation algorithm using a fuzzy segmentation algorithm to map fire extent, active fire front, hot burn scar, and smoke regions based on a statistical model [7].

Due to the restriction of natural condition, such as steep topography, poor sighting condition and large forest area, it is difficult to measure the deforestation area dimension efficiently in real time. Thus, coupled with the technology of digital image processing, we propose a cheap and easy method to monitor and estimate the deforestation area based on the aerial image. The proposed method has two significant steps. First, we scan the targeted area using the google earth application and get the image with the specific distance. Secondly, the targeted area is calculated. So how to extract the target accurately is the key to detecting the deforestation area. This paper focuses on the second step of the algorithm to evaluate the deforestation area using current segmentation method by means of aerial images.

\section{Methodology}

Image segmentation by thresholding is a simple but powerful approach for segmenting images having light objects on dark background. Thresholding technique is based on image space regions i.e. on characteristics of the images [8]. Thresholding operation convert a multilevel image into a binary image and, we choose a proper threshold T, to divide image pixels into several regions and separate objects from the background. Any pixel (x,y) is considered as a part of object if its 
intensity is greater than or equal to threshold value i.e., $\mathrm{f}(\mathrm{x}, \mathrm{y}) \geq \mathrm{T}$, else, the pixel is considered as the background [9]. As per the selection of thresholding value, two types of thresholding methods are in existence [10], global and local thresholding. When $\mathrm{T}$ is constant, the approach is called global thresholding otherwise it is called local thresholding. Global thresholding methods fails when the background illumination is uneven. In local thresholding, multiple thresholds are used to compensate for uneven illumination [11]. Threshold selection is typically done interactively however, it is possible to derive automatic threshold selection algorithms. Fig. 2 below depicts the steps of the proposed method.
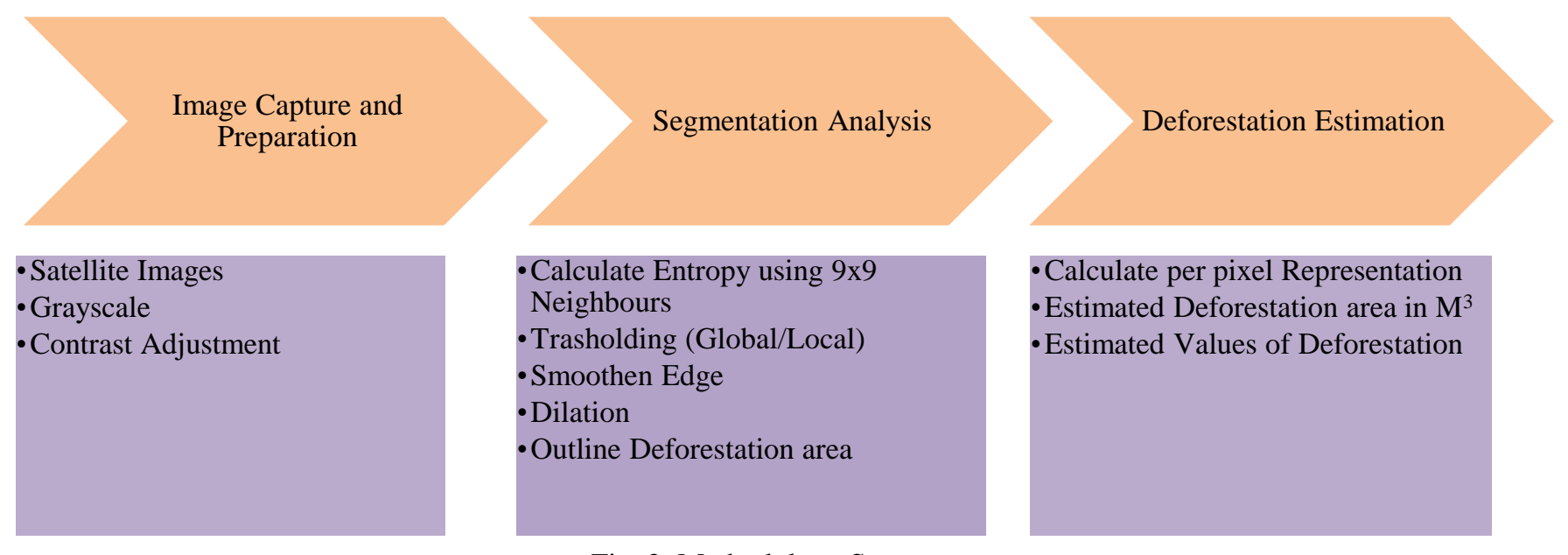

Fig. 2: Methodology Sequence.

Limitation of thresholding method is that, only two classes are generated, and it cannot be applied to multichannel images. In addition, thresholding does not take into account the spatial characteristics of an image hence it is sensitive to noise [4]. Both of these artifacts corrupt the histogram of the image, making separation more difficult. Fig. 3 and Fig. 4 show the process of aerial image transformation into deforestation segmented region. The main objective of the proposed method is to calculate the area of deforestation and evaluate the forest values of that particular affected pixels. To do this, we maintain the forest satellite image at $2.5 \mathrm{KM}$ to the ground. After that, the overall process is accomplished in three phases

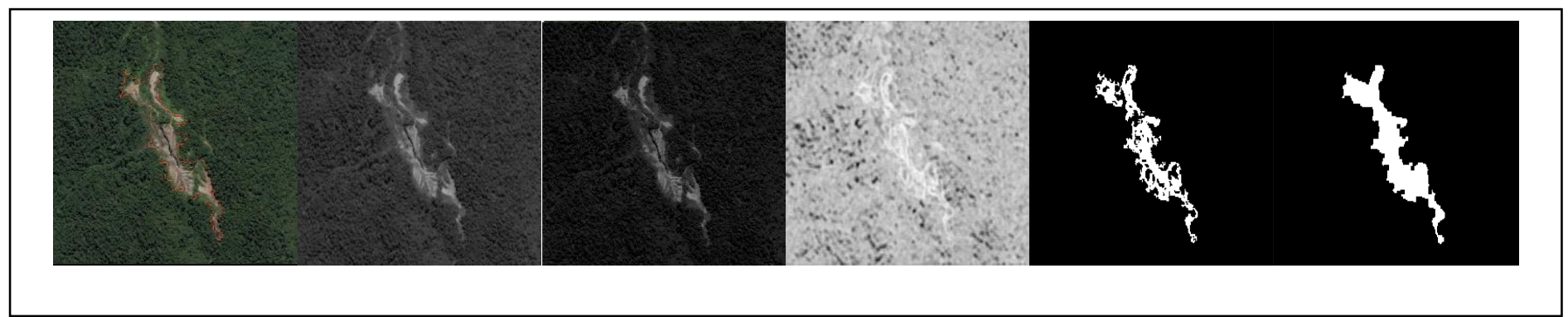

Fig. 3: Process of Satellite Image Transformation.

\section{Phase 1: Step for Converting Satellite Image Deforestation Area}

Step 1: $\quad$ Convert the RGB image into grayscale

Step 2: $\quad$ Adjust the image contrast

Step 3: The entropy function returns an array where each output pixel contains the entropy value of the 9-by-9 neighborhood around the corresponding pixel in the input image. Entropy is a statistical measure of randomness.

Step 4: $\quad$ A threshold value of 0.8 is selected because it is roughly the intensity value of pixels along the boundary between the textures. By using Histogram Dependent Technique (HDT) which is dependent on the success of the estimating the threshold value that separates the two homogenous region of the object and background of an image. This required that, the image formation be of two homogenous and will-separated regions and there exists a threshold value that separated these 
regions. The (HDT) is suitable for image with large homogenous and will separate regions where all area of the objects and background are homogenous and except the area between the objects and background. This technique can be expressed as:

$C(T)=P_{1}(T) \sigma_{1}^{2}(T)+P_{2}(T) \sigma_{2}^{2}(T)$

Where:

$C(T)$ is the within-group variance.

$P_{1}(T)$ is the probability for group with values less than T.

$P_{2}(T)$ is the probability for group with values greater than $\mathrm{T}$.

$\sigma_{1}^{2}(T)$ is the variance of group of pixels with values less than or equal $\mathrm{T}$

$\sigma_{2}^{2}(T)$ is the variance of group of pixels with values greater than T.

Step 5: $\quad$ The edge of the image will be smoothen to close any open holes using image fill function.

Step 6: The dilation of the deforestation texture will be outline by red line to show the land usage area.

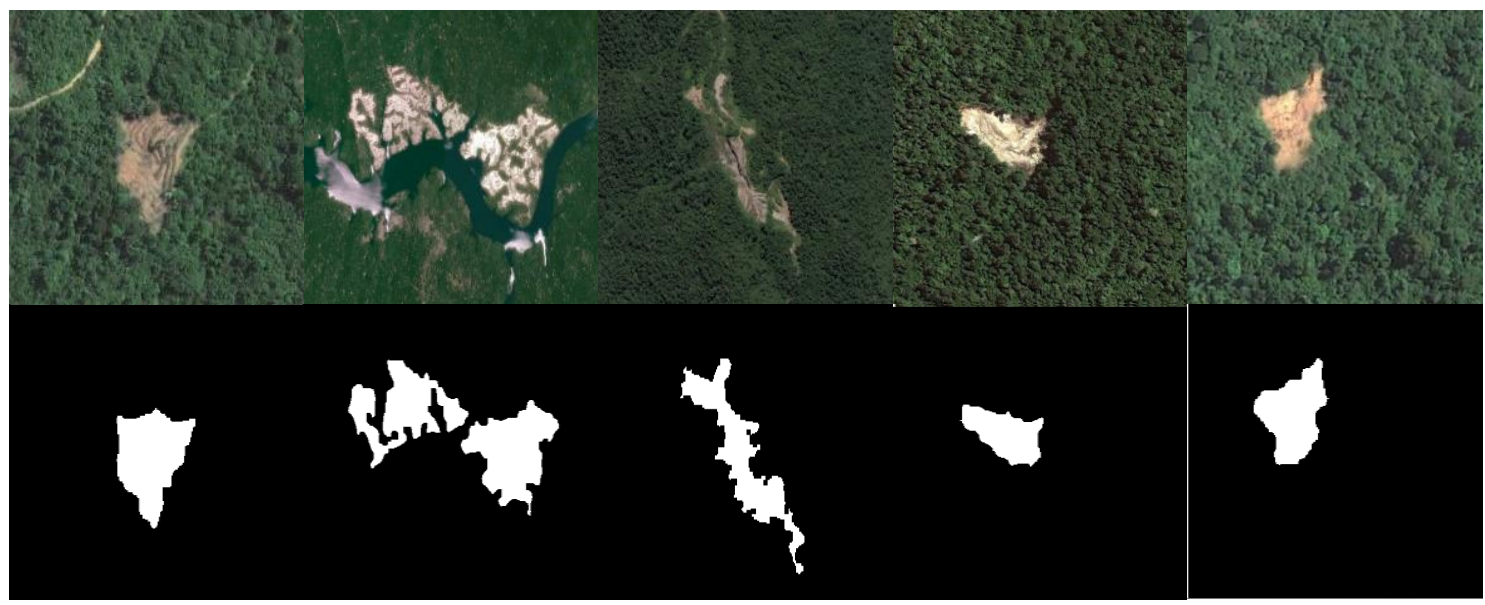

Fig. 4: Aerial View of Deforestation.

\section{Phase 2: Deforestation Estimation Algorithm}

From the segmented image, compute the deforestation area using the algorithm below:

Estimate Total Area $($ ETA $)=$ Width $x$ Length

Estimate Pixel $(E P)=$ Image Width $x$ Image Length

Area Per pixel $(A P)=E T A / E P$

Deforestation Pixel Area $=\sum$ segmented pixel

Area of Deforestation $=D P A * A P$

Original ground width \& length in $\mathrm{m}^{2}$

Example:

$E T A=400 \mathrm{~m} \times 200 \mathrm{~m}=80,000 \mathrm{~m}^{2}$

$E P=600$ pixel $x 800$ pixel $=\quad=480,000$ pixel

$A P=\frac{80000}{480000}=0.17 \mathrm{~m}^{2}$

$D P A=201,000$ pixel

$\therefore$ Area of deforestation: $201000 \times 0.17 \mathrm{~m}^{2}=34,170 \mathrm{~m}^{2}$

\section{Phase 3: Evaluation of Deforestation Area Algorithm}

According to Malaysia Timber Industry Board (MTBI), logs in Malaysia is divided into 4 categories as shown in Table 4. The normal species distribution in Malaysian or tropical forest per acre are consist of $40 \%$ of normal species, $25 \%$ of second standard species, $20 \%$ of first standard species and $15 \%$ of premium species. Average total tonnage per acre (100 meter X 100 meter) is about 45 Tons. 
Table 3. Markets Values for Malaysian Major Logs.

\begin{tabular}{|l|c|c|}
\hline Category & Price Range/Ton $\left(\mathrm{m}^{3}\right)$ USD & Distribution/Acre \\
& & \\
\hline Premium Standard & $>1000$ & $15 \%$ \\
\hline First Standard & $550-750$ & $20 \%$ \\
\hline Second Standard & $350-550$ & $25 \%$ \\
\hline Normal & $250-350$ & $40 \%$ \\
\hline
\end{tabular}

Based on the tabulation in Table 3, the example of deforestation area evaluation are as follow:

Let take Deforestation Area: $=100,000 \mathrm{~m}^{2}$

$\therefore$ Area of deforestation in Acre: $\quad \frac{100000}{10000}=10$ acres

Value /acre $=(15 \% * 1000)+(20 \% * 550)+(25 \% * 350)+(40 \%+250)=500 U S D /$ Acre $/$ Ton

$\therefore$ Total Value $=500 \mathrm{USD} *(45$ Ton/Acre $) * 10$ Acre $=225,000 \mathrm{USD}$

\section{Result and Discussion}

The proposed approach using image segmentation entropy techniques was very effective to detect different texture in the images. In Table 4, the result shows the accuracy mean of $93 \%$ with standard deviation of $4 \%$. Only 12 out of 85 images tested are out of the normal tabulation, and it is shown that the calculation of deforestation area is acceptable. The major factors inaccuracy in the calculation is the uneven surface area of the actual location either hilly or sloppy. To note our method calculates the area with the assumption that it is flat area. Since the standard practice of forest monitoring guidelines state that any accuracy rate above then $85 \%$ is consider good, thus $93 \%$ accuracy derived from the proposed method is acceptable for real life application

Table 4. Accuracy Rate for Deforestation Segmentation.

\begin{tabular}{|l|l|l|r|l|}
\hline \multirow{2}{*}{$\begin{array}{l}\text { Image } \\
\#\end{array}$} & $\begin{array}{l}\text { Ground } \\
\text { Truth } \\
\text { Deforestation } \\
\text { Area }\left(\mathrm{m}^{2}\right)\end{array}$ & $\begin{array}{l}\text { Segmented } \\
\text { Deforestation }\end{array}$ & \multirow{2}{*}{$\begin{array}{l}\text { Difference } \\
\left(\mathrm{m}^{2}\right)\end{array}$} & \multirow{2}{*}{ Accuracy } \\
\cline { 3 - 4 } & & Area $\left(\mathrm{m}^{2}\right)$ & & \\
\hline 1 & $1,360.07$ & $1,481.56$ & 121.49 & $92 \%$ \\
\hline 2 & $6,506.55$ & $5,915.94$ & 590.61 & $91 \%$ \\
\hline 3 & $75,358.41$ & $78,311.52$ & $2,953.11$ & $96 \%$ \\
\hline 4 & $1,380,637.77$ & $1,338,257.73$ & $42,380.04$ & $97 \%$ \\
\hline 5 & $6,252.09$ & 5579.62 & 672.42 & $89 \%$ \\
\hline 6 & $1,405,170.62$ & $1,338,257.73$ & $66,912.89$ & $95 \%$ \\
\hline 7 & $1,574,067.71$ & $1,543,203.64$ & $30,864.07$ & $98 \%$ \\
\hline 8 & $86,774.13$ & $89,457.87$ & $2,683.74$ & $97 \%$ \\
\hline 9 & $128,513.72$ & $123,570.88$ & $4,942.84$ & $96 \%$ \\
\hline 10 & $5,913.59$ & $6,570.65$ & 657.07 & $90 \%$ \\
\hline 11 & $7,766.94$ & $8,442.33$ & 675.39 & $92 \%$ \\
\hline 12 & $10,823.31$ & $10,115.24$ & 708.07 & $93 \%$ \\
\hline 13 & $6,082.33$ & $5,430.65$ & 651.68 & $88 \%$ \\
\hline
\end{tabular}




\section{Conclusion}

In this paper, we propose a method which utilizes satellite images which can be used for forest examination and monitoring of current deforestation activities. This method focuses on aerial image from google earth application and apply adaptive threshold to a grey scale image, and the proposed method achieves a easy, low cost, and accurate monitory estimation of deforestation area value. Future work include further exploration in combining other method such as texture and colour for individual tree recognition with the elevation variables.

\section{References}

[1] L. Merino, F. Gomez-Rodriguez, B. C. Arrue, and A. Ollero, "Aerial monitoring and measurement of forest fires," in Proceedings of SPIE - The International Society for Optical Engineering, Enhanced and Synthetic Vision 2002, April 1-2, 2002, pp. 95-105.

[2] N. M. Robertson and T. Chan, "Aerial image segmentation for flood risk analysis," in Proceedings of International Conference on Image Processing, November 7-12, 2009, pp. 597-600.

[3] M. P. Dubuisson-Jolly and A. Gupta., "Color and texture fusion: Application to aerial image segmentation and GIS updating," Image and Vision Computing, vol. 18, no. 10, pp. 823-832, 2000.

[4] R. A. Butler. (2013, November 15th). Malaysia has the world's highest deforestation rate, reveals Google forest map. [Online]. Available: https://news.mongabay.com/2013/11/malaysia-has-the-worlds-highest-deforestation-rate.

[5] D. Y. Zhang, A. K. Hu, Y. J. Rao, J. M. Zhao, and J. H. Zhao, "Forest fire and smoke detection based on video image segmentation," in Proceedings of SPIE-The International Society for Optical Engineering, MIPPR 2007: Pattern Recognition and Computer Vision, November 15-17, 2007, pp. 67882H.

[6] X. L. Wang, A. P. Jiang, and Y. L. Wang, "A segmentation method of smoke in forest-fire image based on FBM and region growing," in Proceedings of 4th International Workshop on Chaos-Fractals Theories and Applications, October 19-21, 2011, pp. 390-393.

[7] Y. Li, A. Vodacek, and Y. S. Zhu, "An automatic statistical segmentation algorithm for extraction of fire and smoke regions," Remote Sensing of Environment, vol. 108, no. 2, pp. 171-178, 2007.

[8] W. X. Kang, Q. Q. Yang, and R. R. Liang, "The Comparative Research on Image Segmentation Algorithms," in IEEE Conference on ETCS, pp. 703-707, 2009.

[9] L. Aurdal, "Image Segmentation beyond thresholding," Norsk Regnescentral, 2006.

[10] Y. Zhang, H. Qu, and Y. Wang, "Adaptive Image Segmentation Based on Fast Thresholding and Image Merging," Artificial reality and Telexistence-Workshops, pp. 308-311, 1994.

[11] S. S. Varshney, N. Rajpal, and R. Purwar, "Comparative Study of Image Segmentation Techniques and Object Matching using Segmentation," in Proceeding of International Conference on Methods and Models in Computer Science, pp. 16, 2009. 